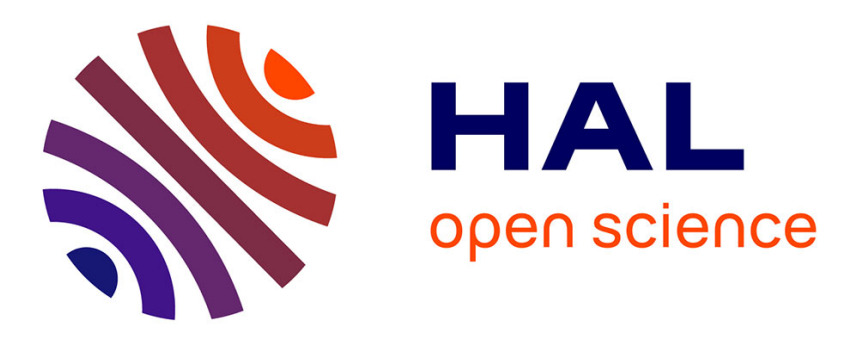

\title{
Modeling the merging capacity for two streams of product returns in remanufacturing systems
}

\author{
Mahdi Fathi, Farshid Zandi, Oualid Jouini
}

\section{To cite this version:}

Mahdi Fathi, Farshid Zandi, Oualid Jouini. Modeling the merging capacity for two streams of product returns in remanufacturing systems. Journal of Manufacturing Systems, 2015, 37, pp.265-276. 10.1016/j.jmsy.2014.08.006 . hal-01265243

\section{HAL Id: hal-01265243 \\ https://hal.science/hal-01265243}

Submitted on 3 Feb 2016

HAL is a multi-disciplinary open access archive for the deposit and dissemination of scientific research documents, whether they are published or not. The documents may come from teaching and research institutions in France or abroad, or from public or private research centers.
L'archive ouverte pluridisciplinaire HAL, est destinée au dépôt et à la diffusion de documents scientifiques de niveau recherche, publiés ou non, émanant des établissements d'enseignement et de recherche français ou étrangers, des laboratoires publics ou privés. 


\title{
Modeling the Merging Capacity for Two Streams of Product Returns in Remanufacturing Systems
}

\author{
Mahdi Fathi ${ }^{1} \bullet$ Farshid Zandi ${ }^{2} \bullet$ Oualid Jouini ${ }^{1}$ \\ ${ }^{1}$ Ecole Centrale Paris, Laboratoire Génie Industriel, Grande Voie des Vignes, 92290 \\ Châtenay-Malabry, France \\ ${ }^{2}$ Department of Industrial Engineering, K.N Toosi University of Technology, Tehran, Iran \\ mahdi.fathi@ecp.fr • f.zandi@sina.kntu.ac.ir • oualid.jouini@ecp.fr
}

Journal of Manufacturing Systems. To appear, 2014

\begin{abstract}
We consider a remanufacturing system with two streams of returned products and different variability levels (high and low). The arrival of returns with high variability is modeled with a hyperexponential renewal process and that of returns with low variability is modeled with a Poisson process. The remanufacturing facility can process the returned products in two ways. For the first way, each type of returns is remanufactured by a dedicated capacity. For the second way, returns from two different markets are remanufactured by a merged capacity.

Analytical queueing models with the time value of money consideration are proposed for the admission decision, which decides on the acceptance or not of returned products based on quality and processing time. The proposed modeling determines the admission decision threshold value in order to maximize the total expected profit of the remanufacturing system. Our analysis also allows to study the interaction between the overall utilization and the arrival process variability. The results show the impact of the model parameters on the admission decision value and the total expected discounted profit. Also, the total expected discounted profit under the separated and merged capacities are compared.
\end{abstract}

Keywords: Remanufacturing; closed loop supply chain; queueing systems; admission decision problem; timevalue. 


\section{Introduction}

Product remanufacturing has been developed rapidly aiming to protect the environment and to reduce production costs in the supply chain. In today's market, consumers are usually allowed to return a purchased product. Many returned products are sometimes remanufactured and reused without even the customer knowledge (Koren, 2010). Due to the large amount of returned products, the manufacturers should consider these returns in the production planning and inventory control processes. This is a new important issue for manufacturing systems. Remanufacturing is defined by Lund and Mundial (1984) as: "An industrial process in which worn out products are restored to seem like new ones". Consider a capacitated facility which remanufactures returns to remarket as remanufactured products. High congestion levels at the remanufacturing facility may cause considerable delays and consequently remarketing value losses for time-sensitive products. By the development of technology, especially among electronic products, the useful lives of products are shortened. Making decision on return of products plays an important role for high remanufacturing costs and short product life cycles. Remanufacturing all returned products might not be possible because of increasing remanufacturing costs according to the spent time.

Admission decision for remanufacturing is based on the quality and the required processing times of returned products. These are the main source of uncertainty. The returned products can be then classified into: waste to be disposed, or material and parts to be used in processes for producing parts and products. One possibility for a heavily-loaded remanufacturing facility, when the queue at the remanufacturing facility becomes too long, is to sell returned products as-is immediately at their salvage value.

Research on remanufacturing systems has been done under various perspectives. Remanufacturing is an important activity in closed loop supply chains (CLSC). Hence it has been successfully practiced in many industries, such as mobile phones, computers, cameras, and photocopiers. Guide and van Wassenhove (2003) further investigated a closed loop supply chain where the quantity, quality, and timing of returns can be controlled by the price offered to buy back the used products. The demand and return rates are assumed to be price-sensitive. Inderfurth (2005) investigated the impact of uncertainties on recovery behavior in a closed loop system. Through a numerical analysis, it is shown that the product recovery management becomes much difficult, as the manufacturer should balance the production, recovery, and disposal decisions under considerable uncertainties of 
demand and return. New integrated models still need to be developed to link various disciplinary perspectives of CLSC (Guide and van Wassenhove, 2009) and the stochastic nature of demand and return should be paid more attention (Pokharel and Mutha, 2009). For other various quantitative studies on CLSC activities, we also refer the reader to Dekker et al. (2004) and Shi et al. (2011).

The motivation for this study is that remanufacturing systems are showing an increasing interest in incorporating the merging as an important input into the closed loop supply chains. Moreover, high congestion levels for returns at remanufacturing facility causes substantial delays and consequently remarketing value losses for time-sensitive products and high-tech products with short life cycles, such as consumer electronic equipment computers and printers. Guide et al. (2006) report that prices of printers decay at $1 \%$ per week. Some PC components decay at even higher rates: $15 \%$ per month for compact flash memories and $8 \%$ per month for disk drives. Also, several recent trends motivate companies to merge the capacities that were previously dedicated to dissimilar demand processes. There are real case studies of such dissimilarity in demand processes such as: the case of Volvo heavy truck division distribution center that was studied by Narus and Anderson (1996), the merging production capacity Alcan Aluminum Ltd. and Arco's Atlantic Ritchfield \& Co. that was studied by Iyer and Jain (2004). Therefore, we believe that the merging perspective is needed to determine the admission decision threshold value that decides about acceptance of returned products to prevent the value losses for time-sensitive products.

In this paper, we focus on a remanufacturing system for a type of short life cycle product with stochastic serviceable demand and stochastic returns. There are two return streams with different variabilities in the process of arrivals, namely we consider a hyper-exponential renewal process and a Poisson process. We use an economic framework and the $\mathrm{M} / \mathrm{M} / 1, \mathrm{H} / \mathrm{M} / 1$, and $\mathrm{H}_{2} \mathrm{M} / \mathrm{M} / 1$ queues to model the considered remanufacturing processes. We determine the admission decision threshold value that decides about the acceptance of returned products on the base of quality and processing time while maximizing the total expected profit. We show that the difference in variability in arrivals has a significant impact on the value of merging capacity. The proposed modeling aims to address the question: When does merging generate Pareto-improving benefits over the separated system?

The reminder of this paper is organized as follows. In Section 2, we survey the literature related to this paper. In Section 3, we give the description of the remanufacturing system under 
consideration. Section 4 is devoted to the problem formulation and the theoretical analysis of the queueing modeling. In Section 5, we conduct a numerical study to illustrate the theoretical results. The paper ends with concluding remarks and directions for future research.

\section{Literature Review}

In the literature, hybrid production processes are modeled using capacitated and incapacitated models. The capacitated and incapacitated models both in manufacturing and remanufacturing processes are modeled as queuing networks with finite production rates (Aksoy and Gupta, 2005; Korugan and Gupta, 1998; van der Laan et al., 1999; Guide et al., 2005).

Ching et al. (2007) studied a Markovian queueing modeling for hybrid manufacturing/remanufacturing systems. They assumed that the arrival of returns follows a Poisson process and there is not any rejection of returns from the system. A matrix geometric method is applied to analyze the resulting queueing network. Inderfurth and van der Laan (2001) studied a remanufacturing system and proposed a model where demands from customers can be satisfied by both new and recovered products. The recovered products were disposed or stocked in a dedicated inventory. Mahadevan et al. (2003) used a similar modeling and proposed pull and push inventory policy for the remanufacturing system. Kiesmüller and van der Laan (2001) considered dependent returned products and customer demands in the remanufacturing system. Karamouzian et al. (2011) provided an analytical queueing analysis to obtain the best policy to accept returned products. Furthermore, a continuous genetic algorithm is implemented to solve the model, which happens to be a mixed integer non-linear mathematical program.

There is a rich literature that investigated production planning and control for remanufacturing, but only a few of these studies considered the quality of returned products. Returns are often assumed to have one single quality level (van der Laan and Salomon, 1997; van der Laan et al., 1999; Toktay et al., 2000; Golany et al., 2001; van der Laan and Teunter, 2006; Ferguson et al., 2006)). Souza et al. (2002) modeled the remanufacturing facility as a multi-class open queueing network where quality levels of returned products determine their classes. They dedicated special remanufacturing stations for different quality type returns. They examined the dispatching rules in remanufacturing stations in order to reduce flow times and improve the service level. Galbreth and Blackburn (2006) considered a remanufacturing system with both deterministic demand and 
random demand under used product variability condition. In order to analyze remanufacturing and disposal decision, Aras et al. (2004) emphasized on quality levels of returned product and constructed a continuous time Markov chain model and investigated quality based remanufacturing lead times and disposal cost. Takahashi et al. (2007) used Markov analysis to study a remanufacturing system where recovered products are decomposed and classified into wasted to be disposed and materials and parts to be used in the processes for producing parts and products. Recently, Jin et al. (2012a) investigated the assembly strategies for product remanufacturing with variation in the quality level of returns. The author studied the optimal policy for the modular product reassembly within a remanufacturing setting where a firm receives returns with different quality levels and reassembles products of multiple classes to customer orders. Moreover, Jin et al. (2012b) modeled performance analysis of a remanufacturing system with warranty return admission.

Behret and Korugan (2005) analyzed a hybrid manufacturing/remanufacturing system under general distributed processing times with different variances. Behret and Korugan (2009)used simulation to analyze a hybrid system under uncertainties in the quality of remanufactured products, return rate and return times. Dobos and Richter (2006) studied the quality of used products in an integrated production recycling system, and showed that it is better for the manufacturer to only buy back reusable products. Also, many applications and methods for analyzing the hybrid manufacturing system are discussed in Bayindir et al. (2003, 2004, 2007), Yamada et al. (2009), Aksoy and Gupta (2005), and Ketzenberg et al. (2003).

Numerous recent trends motivate companies to merge their capacities which were previously dedicated to dissimilar demand processes. There are real case studies of such dissimilarity in demand processes. Gupta and Gerchak (2002) provided several examples on the issue of operational synergies in a merger/acquisition between parties with different characteristics. Narus and Anderson (1996) studied the case of Volvo heavy truck division distribution center which has separate distribution capacities to serve urgent and scheduled orders. It should be noted that the urgent orders have more variability than the scheduled ones. Eisenstein and Iyer (1996) discussed the Chicago school system in which two separated distribution capacities and warehouses were used to serve demands with different levels of predict ability. Fisher (1997) investigated two product types with different variabilities in demand: functional and innovative. The demand processes of functional products are less variable than the innovative products. Lee and Tang (1997) studied 
modularization and part commonality term in manufacturing systems and suggested that the redesigned parts can be produced at the same manufacturing capacity. Consequently, the separate production processes for parts can be removed. Jain (2007) considered the value of merging in supply chains which serve product demands with different variability and analyzed models which integrate production queueing models with base stock inventory systems serving demands with different inter-arrival time distributions. Recently, Flapper et al. (2014) used Markov decision processes to analyze a hybrid manufacturing-remanufacturing system in which demand and used products arrive via mutually independent Poisson processes. Manufacturing and remanufacturing operations are executed by a single shared resource.

There are few researches in which economic aspect of remanufacturing systems is considered. Geyer et al. (2007) studied the economics of remanufacturing under limited component durability and finite product life cycles. Also, Guide et al. (2008) proposed a two-step heuristic policy for a busy remanufacturing facility. In a first step, the returned product's random processing time is observed and in a second step a disposition decision is made: if the processing time is larger than a specified value, the product is salvaged; otherwise, the product is remanufactured. Harrison (1975) considered the dynamic scheduling problem for the multi-class single server queueing system with discounted rewards. Guide et al. (2008) applied Harrison's result to the problem with positive salvage value.

Queueing theory has been extensively adopted to analyze a variety of performance analysis problems in manufacturing systems (Govil and Fu, 1999; Altiok, 1989). Queueing models, in turn, can be categorized as descriptive (provide values for performance measures of interest for a given configuration) or prescriptive (provide guidelines for running the system most effectively). Govil and $\mathrm{Fu}$ (1999) conducted a comprehensive survey on queueing models for manufacturing applications. Markovian queueing models lead to a useful tool for modeling manufacturing systems in general (Ching, 2001) and flexible manufacturing systems in particular (Ching et al., 2003).

The above literature does not consider the impact of delays in the remanufacturing facility and does not consider the decay rate in price for time-sensitive products and high-tech products with short life cycles. In this paper, we provide an analytical queueing model for the optimal disposition decision for product returns in a remanufacturing system. It is assumed that a returned product is first tested and would consequently be remanufactured. The proposed model tries to 
find the optimal disposition decision for product returns by providing an approximate procedure to compute the optimal threshold value on the processing time. It also considers the quality of returned products for remanufacturing. We moreover examine whether merged remanufacturing capacity can increase the revenue at each returned product stream and determine a Pareto improving region. Our proposed modeling differs from the studied papers in several ways. First, the returned products come from two different markets with different arrival variabilities. Second, the merging of facility remanufacturing capacity is investigated. Finally, the time value of money and remarketing value losses for time-sensitive products and high-tech products with short life cycles are taken into account.

\section{Problem Description and Notations}

Consider a hybrid make-to-stock production system. It consists of two independent manufacturing and remanufacturing processes where the first manufactures new products from raw materials while the second remanufactures returned items. The finished products coming from manufacturing or remanufacturing are stored in a common central warehouse, from which a random customer demand is satisfied. Two demand classes are considered, namely the domestic market (distribution companies, Market H) and the international market (export department, Market M). Figure 1(a) illustrates the proposed model. At the remanufacturing system, returned products are first inspected and classified according to their quality and processing time, and are then remanufactured using a single server facility (Figure 1(b)).

We assume that the arrival process of returned products from market $\mathrm{M}$ have lower variability than that from market H. As commonly used in the literature (Zipkin, 2000; Ha, 1997), the arrival of returned products from Market M is assumed to follow a Poisson process with mean rate $\lambda_{m}$. The inter-arrival times between two successive returns from Market $\mathrm{H}$ is assumed to follow a hyperexponential distribution with mean intensity $\lambda_{h}$ and coefficient of variation $h c v$. The choice of the hyperexponential distribution comes from the fact that it has a coefficient of variation higher than 1 (coefficient of variation of an exponential distribution), which allows to make the difference between the variabilities of the two return processes.

The capacitated remanufacturing facility can refurbish the two types of returned products in two manners. A separated way where each type is remanufactured with a dedicated capacity, 


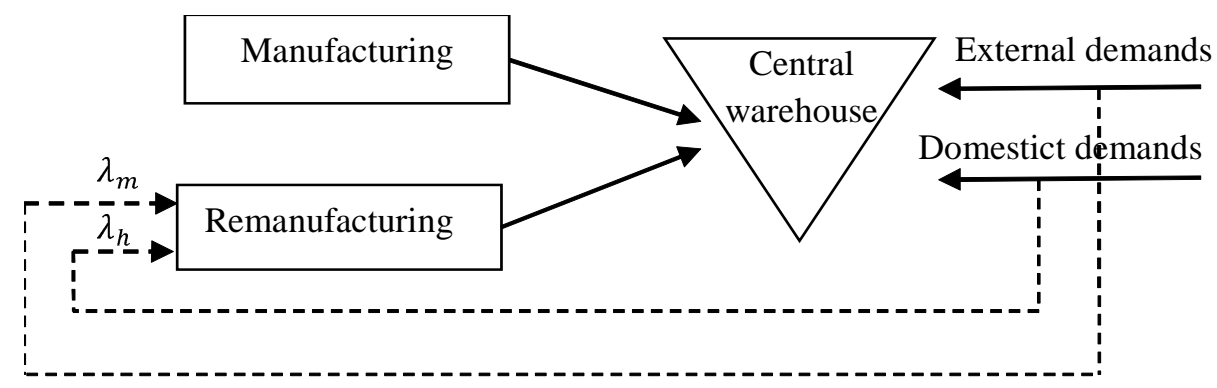

Returns

(a) Hybrid make-to-stock production system with central warehouse

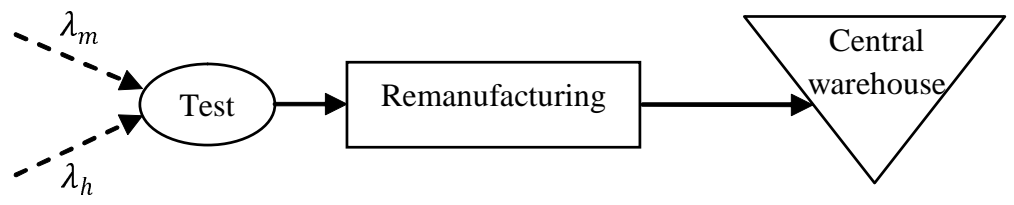

(b) Testing stage and remanufacturing model with two return streams

Figure 1: Framework for hybrid manufacturing/remanufacturing system

and a merged way where the returned products from the two types join the same queue and wait to be remanufactured. In the separated system, each returned product stream has a dedicated remanufacturing capacity. The separated remanufacturing system is modeled as an $M / M / 1$ queue for market $\mathrm{M}$, and as an $H / M / 1$ queue for market $\mathrm{H}$. In the merged system, the two streams of returned products join a single FCFS queue. The merged system is modeled as a $H_{2} M / M / 1$ queue. Through this modeling, a benefit-cost function for the remanufacturing system is presented. The proposed cost function uses a threshold value as a measure to analyze and determine an admission decision for returned products. Further details on the demand modeling and the testing stage are given next in Sections 3.1 and 3.2, respectively. For ease of presentation, we give in what follows the list of the notations used for the analysis in this paper.

\section{Notations:}

$k_{m}$ : threshold value for an external market returned product in the separated system (minute), $k_{h}$ : threshold value for a domestic market returned product in the separated system (minute), $k_{m}^{M}$ : threshold value for an external market returned product in the merged system (minute), $k_{h}^{M}$ : threshold value of a domestic market returned product in the merged system (minute), $\lambda_{h}$ : rate of product returns from the domestic market $\left(\right.$ minute $\left.^{-1}\right)$, $\lambda_{m}$ : rate of product returns from the external market $\left(\right.$ minute $\left.^{-1}\right)$, 
$\mu_{h}$ : rate of the single exponential remanufacturing server for a product returned from the domestic market $\left(\right.$ minute $\left.^{-1}\right)$,

$\mu_{m}$ : rate of the single exponential remanufacturing server for a product returned from the external market $\left(\right.$ minute $\left.^{-1}\right)$,

$\mu$ : rate of the single exponential remanufacturing server $\left(\right.$ minute $\left.^{-1}\right), \mu=\mu_{h}+\mu_{m}$,

$\rho_{h}^{M}$ : traffic intensity in the remanufacturing queue due to returned products from the domestic market in the merged system, $\rho_{h}^{M}=\frac{\lambda_{h}}{\mu}$,

$\rho_{m}^{M}$ : traffic intensity in the remanufacturing queue due to returned products from the external market in the merged system, $\rho_{m}^{M}=\frac{\lambda_{m}}{\mu}$,

$\rho^{M}$ : total traffic intensity in the remanufacturing queue in the merged system, $\rho^{M}=\rho_{m}^{M}+\rho_{h}^{M}<1$, $p$ : salvage value (dollar/unit),

$r$ : obtained revenue from remanufacturing a returned product (dollar/unit),

$\gamma$ : the regular discount rate,

$\alpha$ : the revenue decay rate,

$\beta$ : the overall discount rate $(\beta=\alpha+\gamma)$.

\subsection{Demand Modeling}

The use of the hyperexponential distribution is common in the queueing literature for the modeling of high variability and superposition of high variability arrival processes (see for example Albin (1984); Whitt (1993)). It is used to model high variability distributions in the inventory literature and make-to-stock queueing models (Perez and Zipkin, 1997). Moreover, this modeling can be applied to time varying rate situations, where the corresponding arrival process is a non-homogeneous Poisson process. It should be noted that this arrival process is alternatively on and off for exponential periods. The hyperexponential distribution can be applied for differentiating between the variability of two demand processes based on the single parameter $h c v$.

According to Iyer and Jain (2003), the returned product stream of the domestic market can be modeled as a renewal process where the inter-arrival times follow a hyperexponential distribution of two degrees $\left(H_{2}\right)$. This distribution is a probabilistic mixture of two exponential distributions. It has four parameters $k_{1}, k_{2}, r_{1}$ and $r_{2}$. Its probability density function (pdf), denoted by $a($.$) , is$ 
given by

$$
a(t)=k_{1} r_{1} e^{-r_{1} t}+k_{2} r_{2} e^{-r_{2} t}
$$

where $0 \leq k_{1}, k_{2} \leq 1$ and $k_{1}+k_{2}=1$, and $t \geq 0$. The cumulative distribution function (cdf) of $H_{2}$, denoted by $A($.$) , is given by$

$$
A(t)=1-k_{1} e^{-r_{1} t}-k_{2} e^{-r_{2} t},
$$

for $t \geq 0$. Applying the Laplace transform on Equation (2) leads to

$$
\zeta(z)=\frac{k_{1} r_{1}}{r_{1}+z}+\frac{k_{2} r_{2}}{r_{2}+z}
$$

for $z \geq 0$. The balanced mean assumption is primarily used to reduce the number of parameters describing the hyperexponential distribution from three to two; the mean and the coefficient of variation (Whitt, 1993). Using the normalization $\frac{k_{1}}{r_{1}}=\frac{k_{2}}{r_{2}}$, the parameters of $H_{2}$ are displayed next in Equations (4) and (5) (Tijms, 1986).

$$
\begin{gathered}
k_{1}=0.5\left(1+\sqrt{\frac{(h c v)^{2}-1}{(h c v)^{2}+1}}\right) ; \quad r_{1}=2 k_{1} \lambda_{h}, \\
k_{2}=1-k_{1} \quad, \quad r_{2}=2 k_{2} \lambda_{h} .
\end{gathered}
$$

Let $c=2\left(k_{1}^{2}+k_{2}^{2}\right)$. The parameter $c$ is a measure of variability of the market $\mathrm{H}$ demand process where $1 \leq c<2$. By definition, a hyperexponential distribution has $h c v \geq 1$, and this mapping from $h c v$ to $c$ allows to compress the entire variability range to $1 \leq c<2$ which would simplify further the analysis. Note that $c$ is increasing in $h c v$ and the hyperexponential distribution degenerates into an exponential distribution when $h c v=1$.

\subsection{Testing Stage as a Class Differentiation}

In this section, we discuss about the threshold value for the admission decision and also the different classes of returned products to the single testing stage. The results about separated capacity and merged capacity are discussed next in Sections 4.1 and 4.2. The returned products are not exogenous to the remanufacturing problem. Required time and materials to restore the product as a new product by remanufacturing depend on returns condition and quality (Guide et al., 2003; Guide and van Wassenhove, 2003). Returned products from each market are different in terms 
of their functionalities and types. Hence, incoming returns are different in terms of quality and consequently in terms of processing times. The remanufacturing process time for all returns from different markets is drawn from the same distribution with different rates.

In the considered remanufacturing system, there is an inspection stage with infinite capacity (i.e., with no delay) that determines the required processing time of the returned product. The remanufacturing process time estimated by the testing stage is used to make the admission decision. All the returned products with a processing time greater than a threshold value (denoted by $k$ ) are rejected from the remanufacturing process, while those with an estimated processing time less or equal to $k$ are remanufactured. The threshold value $k$ divides the returned products into two classes: Class 1 returned products comprises products with a remanufacturing time less or equal to $k$ which are admitted to the remanufacturing process. Products with a remanufacturing time higher than $k$ constitute Class 2 returned products that are rejected (recycled). Figure 2 represents this decision problem in accordance with Guide et al. (2008).

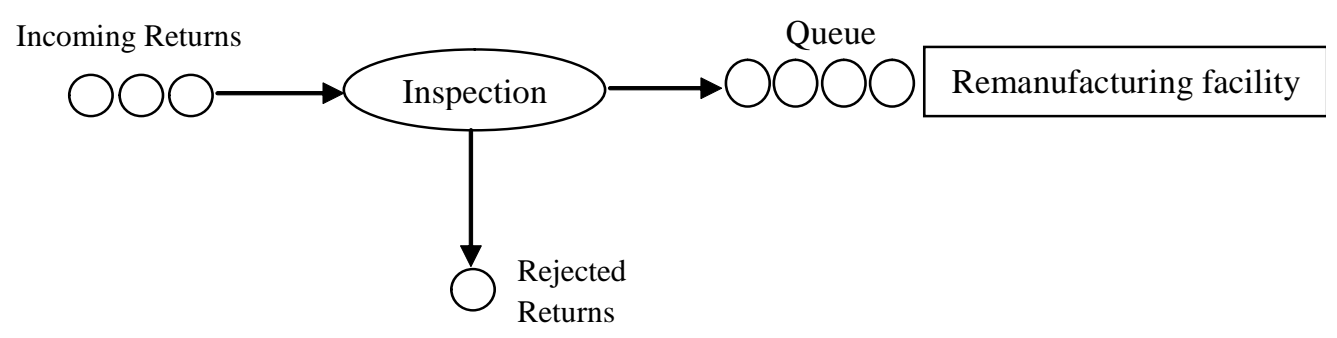

Figure 2: Admission control of returned products

\section{Problem formulation}

This section is devoted to the mathematical formulation of the model. The separated and merged remanufacturing models are analyzed in Sections 4.1 and 4.2, respectively.

\subsection{Separated Remanufacturing Model}

In the separated system, each returned stream from a market joins a dedicated remanufacturing queueing system with its own dedicated capacity. As mentioned in Section 3.2, there exist two options at the arrival of a returned product: to admit it in the queue and obtain revenue $r$ at its completion, or to reject it and sell it at a salvage value $p$. It is assumed that a unit revenue for 
a completed remanufactured product decreases exponentially with time. According to the remanufacturing system studied by Guide et al. (2008) and Harrison (1975), the revenue per completed remanufactured product at time $t$ is, $r e^{-\beta t}$ where $\beta$ is the overall discount rate. There are no explicit holding costs. Holding costs are implicitly defined in the overall discount rate $\beta$. This method is used for example by Harrison (1975) for the optimal static policy that ranks the classes of returned products with salvage value 0. Guide et al. (2008) use a similar modeling to that of Harrison in the context of returns from one market.

The remanufacturing processing time for all returned products is a random variable, denoted by $X$ with $\operatorname{cdf} F(x)$, for $x \geq 0$. The remanufacturing processing time is estimated by the incapacitated testing stage, and the admission decision is determined through a threshold value on the processing time (Figure 3).

A returned product is accepted with probability $P\left(X \leq k_{i}\right)=F\left(k_{i}\right)$, for $i \in\{m, h\}$. Therefore, the mean arrival rate of accepted returned products (Class 1) is $\lambda_{i} P\left(X \leq k_{i}\right)=\lambda_{i} F\left(k_{i}\right)$, and that of rejected ones (Class 2) is $\lambda_{i} P\left(X>k_{i}\right)=\lambda_{i}\left(1-F\left(k_{i}\right)\right)$.

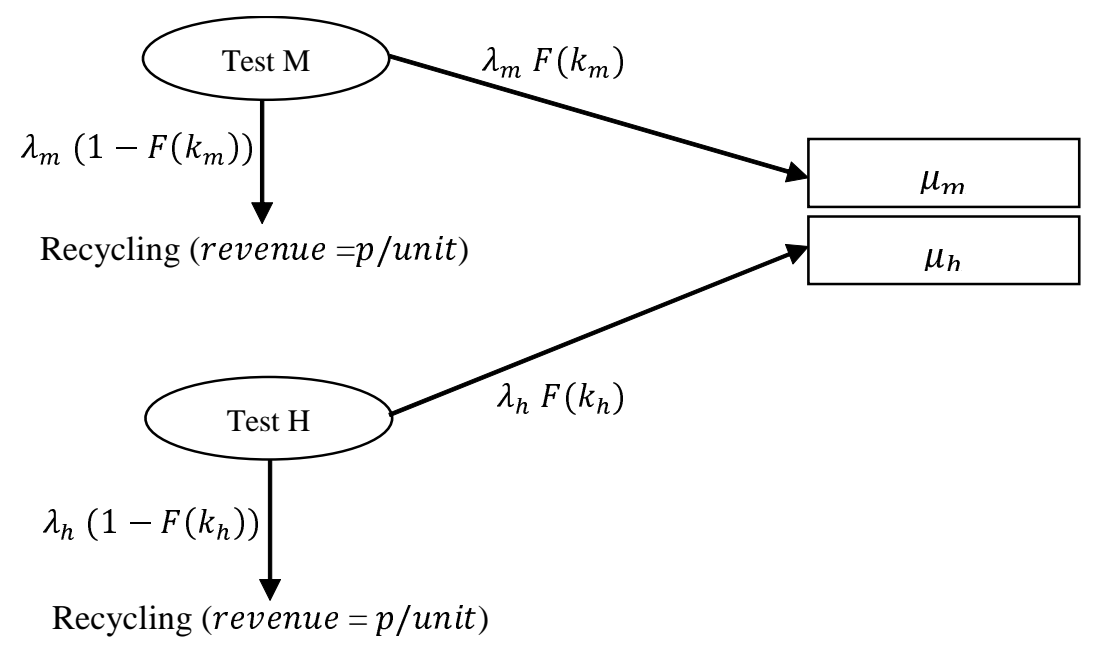

Figure 3: The separated remanufacturing system

The pdf of the remanufacturing processing time for an accepted returned product (Class 1) is $f_{1}(x)=\frac{f(x)}{F(k)}$, for $0 \leq x \leq k$ and 0 otherwise. In the separated capacity system, the two return streams are remanufactured by their own dedicated remanufacturing capacity. Thus the two queueing systems of interest are $H_{2} / M / 1$ for high variability returns and $M / M / 1$ for low variability returns.

We focus on the steady state analysis of the queueing model as shown in Figure 3. The re- 
manufacturing cost per unit is a function of the observed remanufacturing time $x$ for that unit. Since unit prices for remanufactured products are independent of $x$, but decay exponentially with time $t$, net revenue per completed returned product (price minus cost) at time $t$ depends on its remanufacturing time $x$ according to $r(t, x)=r_{0}(x) e^{-\alpha t}$, where $\alpha$ is the net revenue decay rate parameter. It is important to mention that the proposed model focuses on discount and decay rate of the returned products in the time at which returned products are in the remanufacturing system. The additional assumption is that the time of holding (inventory) and waiting to transport from market to the manufacturing places are equal to zero. The expected flow time of an accepted returned product from Market $\mathrm{M}$ through the remanufacturing process is the expected flow time in an $M / M / 1$ queue. From Gross et al. (2013), it may be written as $W\left(k_{m}\right)=\frac{1}{\mu_{m}-\lambda_{m} F\left(k_{m}\right)}$.

We denote by $V_{m k}$ the total expected discounted profit with a continuous regular discount rate $\gamma$, over an infinite horizon. We have

$$
\begin{aligned}
V_{m k}= & \lambda_{m} F\left(k_{m}\right) \int_{0}^{\infty} \int_{0}^{k_{m}} r\left(t+W\left(k_{m}\right), u\right) f_{1}(u) e^{-\gamma\left(t+W\left(k_{m}\right)\right)} \mathrm{d} u \mathrm{~d} t \\
& +\lambda_{m}\left(1-F\left(k_{m}\right)\right) p \int_{0}^{\infty} e^{-\gamma t} \mathrm{~d} t \\
= & \lambda_{m} F\left(k_{m}\right) \int_{0}^{\infty} \int_{0}^{k_{m}} r_{0}(u) \frac{f(u)}{F(k)} e^{-\beta\left(t+W\left(k_{m}\right)\right)} \mathrm{d} u \mathrm{~d} t \\
& \quad+\lambda_{m}\left(1-F\left(k_{m}\right)\right) \frac{p}{\gamma} \\
= & \frac{\lambda e^{-\beta\left(W\left(k_{m}\right)\right)}}{\beta} \int_{0}^{k_{m}} r_{0}(u) f(u) \mathrm{d} u+\frac{\lambda p\left(1-F\left(k_{m}\right)\right)}{\gamma} .
\end{aligned}
$$

The optimal threshold value, $k_{m}^{*}$, can be computed through a numerical method ensuring that the total expected discounted profit is maximized, i.e.,

$$
k_{m}^{*}=\arg \max \left(V_{m k}\right)
$$

The expected flow time of an accepted returned product from Market $\mathrm{H}$ through the manufacturing process is the expected flow time in an $H_{2} / M / 1$ queue. Using Iyer and Jain (2004) (see the proof of Proposition 3.5, page 1088), we state that

$$
W\left(k_{h}\right)=\frac{1}{\mu_{h}-\mu_{h} \omega_{2}^{s}}
$$

where $\omega_{2}^{s}$ is the unique root in $(0,1)$ of the equation $\omega=\zeta\left[\mu_{h}(1-\omega)\right]$. We denote by $V_{h k}$ the total 
expected discounted profit with a continuous regular discount rate $\gamma$, over an infinite horizon. We have

$$
\begin{aligned}
V_{h k}= & \lambda_{h} F\left(k_{h}\right) \int_{0}^{\infty} \int_{0}^{k_{h}} r\left(t+W\left(k_{h}\right), u\right) f_{1}(u) e^{-\gamma\left(t+W\left(k_{h}\right)\right)} \mathrm{d} u \mathrm{~d} t \\
& +\lambda_{h}\left(1-F\left(k_{h}\right)\right) p \int_{0}^{\infty} e^{-\gamma t} \mathrm{~d} t \\
= & \lambda_{h} F\left(k_{h}\right) \int_{0}^{\infty} \int_{0}^{k_{h}} r_{0}(u) \frac{f(u)}{F\left(k_{h}\right)} e^{-\beta\left(t+W\left(k_{h}\right)\right)} \mathrm{d} u \mathrm{~d} t \\
& \quad+\lambda_{h}\left(1-F\left(k_{h}\right)\right) \frac{p}{\gamma} \\
= & \frac{\lambda e^{-\beta\left(W\left(k_{h}\right)\right)}}{\beta} \int_{0}^{k_{h}} r_{0}(u) f(u) \mathrm{d} u+\frac{\lambda p\left(1-F\left(k_{h}\right)\right)}{\gamma} .
\end{aligned}
$$

The optimal value of the threshold value $k_{h}^{*}$ can be again computed through a numerical method ensuring that the total expected discounted profit is maximized.

The random flow time is approximated for each return stream with its expected value $W\left(k_{i}\right)$, for $i \in\{m, h\}$. Therefore the obtained optimal value of the threshold value, $k_{i}^{*}$, is an approximated

value. One may use simulation to obtain the exact value of $k_{i}^{*}$. The simulation procedure is however computationally more burdensome while the approximation approach can be implemented in a spreadsheet. More details and an illustration of this approximation is given later in Section 5 .

\subsection{Merged Remanufacturing Model}

In the merged capacity system, the remanufacturing capacities are combined into a single capacity which is modeled as a single exponential server. The inspection system of each market continues to have separate ownership (revenue and salvage value of each market are independent). The returned products from two markets join a single queue which is served by the merged capacity server. Figure 4 shows the merged capacity system.

The analysis of the merged system requires the analysis of the $H_{2} M / M / 1$ queue with a FCFS discipline of service. Similarly to the separated system, an economic framework is used. The expected flow time of an accepted returned product from external market through the remanufacturing process is the expected flow time in an $H_{2} M / M / 1$ queue. Using Iyer and Jain (2004) (see Lemma 3.2, page 1087), we obtain

$$
W\left(k_{m}^{M}\right)=\frac{\left(1-u_{1}\right)\left(1-\rho^{M} u_{1}\right)}{\mu \rho_{h}^{M}\left(1-\rho^{M}\right)(2-c) u_{1}^{2}}
$$




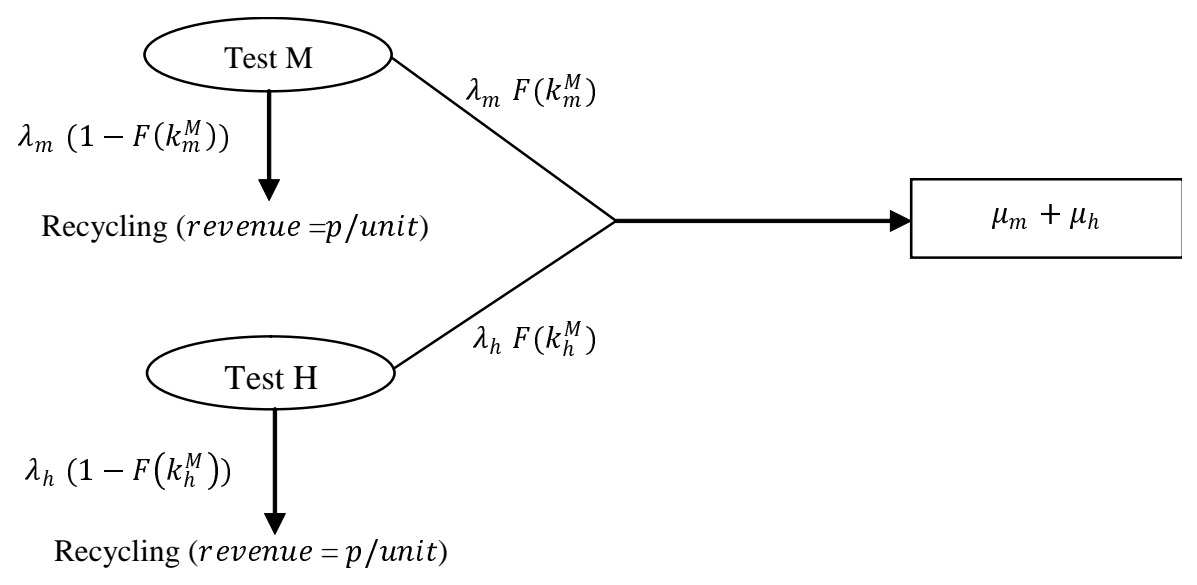

Figure 4: The merged remanufacturing system

where $u_{1}$ is one of the three roots of $\rho_{m}^{M}\left(\rho_{m}^{M}+c \rho_{h}^{M}\right) u^{3}-\left(\left(\rho_{m}^{M}\right)^{2}+2 \rho_{m}^{M}+2 \rho_{m}^{M} \rho_{h}^{M}+2\left(\rho_{h}^{M}\right)^{2}+c \rho_{h}^{M}(1-\right.$ $\left.\left.\rho_{h}^{M}\right)\right) u^{2}+\left(1+2 \rho_{m}^{M}+2 \rho_{h}^{M}\right) u-1=0$ (see Appendix A in Iyer and Jain (2004)).

We denote by $V_{m k}^{m}$ the total expected discounted profit with a continuous regular discount rate $\gamma$, over an infinite horizon. Thus

$$
\begin{aligned}
V_{m k}^{M}= & \lambda_{m} F\left(k_{m}^{M}\right) \int_{0}^{\infty} \int_{0}^{k_{m}^{M}} r\left(t+W\left(k_{m}^{M}\right), u\right) f_{1}(u) e^{-\gamma\left(t+W\left(k_{m}^{M}\right)\right)} \mathrm{d} u \mathrm{~d} t \\
& +\lambda_{m}\left(1-F\left(k_{m}^{M}\right)\right) p \int_{0}^{\infty} e^{-\gamma t} \mathrm{~d} t \\
= & \lambda_{m} F\left(k_{m}^{M}\right) \int_{0}^{\infty} \int_{0}^{k} r_{0}(u) \frac{f(u)}{F(k)} e^{-\beta\left(t+W\left(k_{m}^{M}\right)\right)} \mathrm{d} u \mathrm{~d} t \\
& \quad+\lambda_{m}\left(1-F\left(k_{m}^{M}\right)\right) \frac{p}{\gamma} \\
= & \frac{\lambda e^{-\beta\left(W\left(k_{m}^{M}\right)\right)}}{\beta} \int_{0}^{k} r_{0}(u) f(u) \mathrm{d} u+\frac{\lambda p\left(1-F\left(k_{m}^{M}\right)\right)}{\gamma} .
\end{aligned}
$$

Also using Iyer and Jain (2004), the expected flow time of an accepted returned product from Market $\mathrm{M}$ through the remanufacturing process is

$$
W\left(k_{h}^{M}\right)=\frac{\mu\left(1-\rho_{m}^{M}\right) W\left(k_{m}^{M}\right)-1}{\mu \rho_{h}^{M}}=\frac{\left(1-\rho_{m}^{M}\right)\left(1-u_{1}\right)\left(1-\rho^{M} u_{1}\right)-\rho_{h}^{M}\left(1-\rho^{M}\right)(2-c) u_{1}^{2}}{\mu \rho_{h}^{M^{2}}\left(1-\rho^{M}\right)(2-c) u_{1}^{2}} .
$$

We denote by $V_{h k}^{m}$ the total expected discounted profit with a continuous regular discount rate $\gamma$, 
over an infinite horizon. Therefore

$$
\begin{aligned}
V_{h k}^{M}= & \lambda_{m} F\left(k_{h}^{M}\right) \int_{0}^{\infty} \int_{0}^{k_{h}^{M}} r\left(t+W\left(k_{h}^{M}\right), u\right) f_{1}(u) e^{-\gamma\left(t+W\left(k_{h}^{M}\right)\right)} \mathrm{d} u \mathrm{~d} t \\
& +\lambda_{h}\left(1-F\left(k_{h}^{M}\right)\right) p \int_{0}^{\infty} e^{-\gamma t} \mathrm{~d} t \\
= & \lambda_{m} F\left(k_{h}^{M}\right) \int_{0}^{\infty} \int_{0}^{k_{h}^{m}} r_{0}(u) \frac{f(u)}{F(k)} e^{-\beta\left(t+W\left(k_{h}^{M}\right)\right)} \mathrm{d} u \mathrm{~d} t \\
& \quad+\lambda_{h}\left(1-F\left(k_{h}^{M}\right)\right) \frac{p}{\gamma} \\
= & \frac{\lambda e^{-\beta\left(W\left(k_{h}^{M}\right)\right)}}{\beta} \int_{0}^{k_{h}^{M}} r_{0}(u) f(u) \mathrm{d} u+\frac{\lambda p\left(1-F\left(k_{h}^{M}\right)\right)}{\gamma} .
\end{aligned}
$$

The total expected discounted profit is obtained from Equations (6), (9), (11) and (13). Similarly to the previous section, the above analysis leads to $k_{i}^{*}$, for $i \in\{m, h\}$.

\section{$5 \quad$ Numerical Study and Sensitivity Analysis}

In this section, we numerically illustrate the analysis of Section 4. Our objective is to gain understanding of the impact of the model parameters such as returns rate, remanufacturing facility rate, remanufacturing net revenue curve, regular discount rate, revenue decay rate and overall discount rate, on the admission decision and the total expected discounted profit. We also compare between the total expected discounted profits under the two situations of separated and merged capacities.

We moreover examine whether merging remanufacturing capacity will increase the total expected discounted profit which is Pareto-improving. Unit remanufacturing cost for a completed returned product increases with time but profit of this refurbished product is constant. Therefore, the cost-revenue curve can be obtained. According to the real case of Pitney Bowes and Robert Bosch Power Tools (studied by Guide et al. (2008)), a quadratic function is used for the net revenue curve $r_{0}(x)=b_{2} x^{2}+b_{1} x+b_{0}$. As shown in Figure 5 , four shapes are considered for the remanufacturing net revenue curve. They represent four different trends of increasing in remanufacturing cost with time. In all curves, $b_{0}$ is constant at 80 . This is the net margin defined as price minus remanufacturing costs for a product with zero remanufacturing time. 


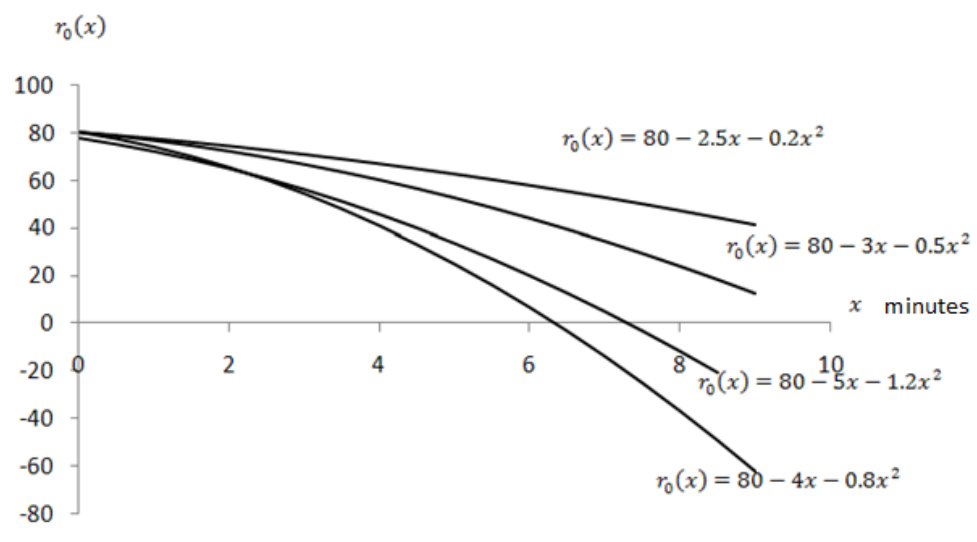

Figure 5: Remanufacturing cost-time

\subsection{Analysis of the Separated System}

In the separated system, there are two separated queueing remanufacturing systems from markets $\mathrm{H}$ and M. For each stream of returned product, the threshold value $k_{i}$, profit $V_{i}$ and acceptance percentage $F\left(k_{i}\right)$, for $i \in\{m, h\}$, of a returned product are calculated for different values of returns rate $\lambda_{i}$. We choose the regular discount rate $\gamma$, the revenue decay rate $\alpha$, and the salvage value of external returns $p$ as $\gamma=0.003, \alpha=0.02$ and, $p=3$, respectively.

Equations (6) and (9) are non-linear equations and hard to solve. According to Equation (7), the optimal value of the threshold $k_{i}^{*}$ can be computed using a numerical method that allows to maximize the total expected discounted profit. Figure 6 provides the plot of Equations (6) and (9) versus $k_{i}$, for $\mu_{i}=0.6$ and $\lambda_{i}=0.5, i \in\{m, h\}$. Initially we observe an ascending trend in both functions to reach a maximum value and then a descending trend. For the threshold $k_{m}^{*}=10.8$, the maximum of Equation (6) is equal to 1158.7 and with increasing the threshold value the function gradually decreases. Equation (9) has the same trend as Equation (6) and a maximum value equal at 50772.00 for $k_{h}^{*}=0.6$. When the remanufacturing system does not accept any of the returned products $\left(k_{i}=0\right)$ the profit value is negative (small value close to zero) for Market $\mathrm{H}$, while it is positive for Market $\mathrm{M}\left(V_{k m}=200\right)$.

Now, we should discuss about the sensitivity analysis of the threshold value and the expected profit function. The results are shown in Figures $7(\mathrm{a})$ and $7(\mathrm{~b})$ with $\mu_{m}=0.7$ and $\lambda_{m}=0.5$. Figure 7(a)-1 reveals that the returned product rate with a constant remanufacturing rate leads to decreasing the threshold value. From Figure 7(a)-2, it leads to increasing the expected profit. Figure 7(a)-3 reveals that it increases the acceptance percentage. Moreover, Figures 7(b)-1, 7(b)-2 


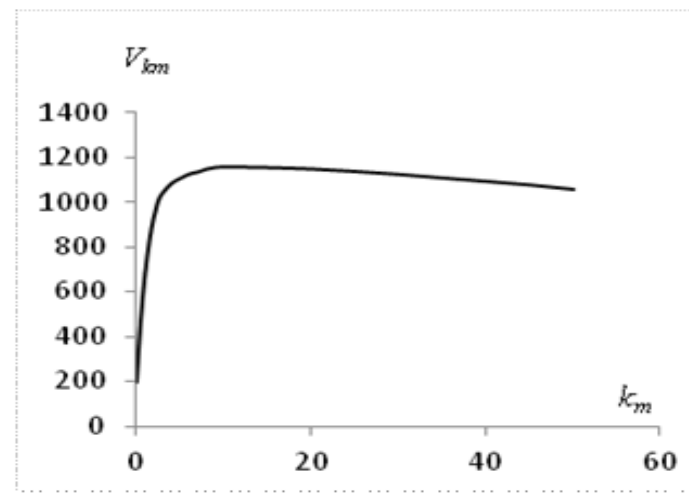

(a) Market M

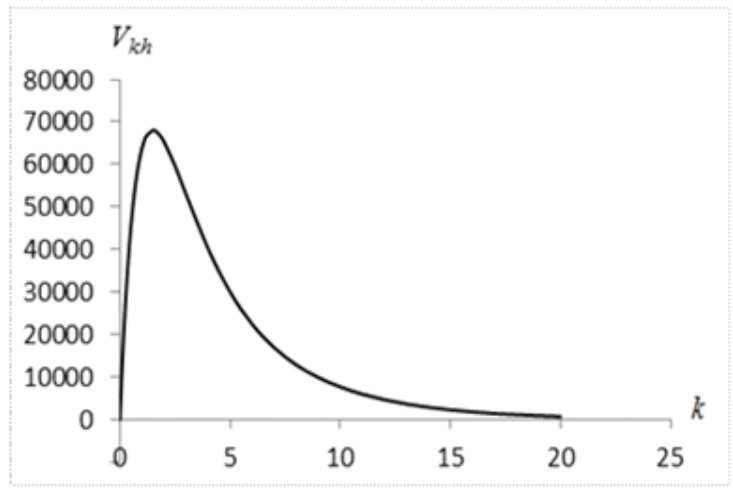

(b) Market $\mathrm{H}$

Figure 6: The expected profit versus different threshold values $k_{i}(\gamma=0.003, \alpha=0.02$ and $p=3$ and $\left.r_{0}(x)=80-2.5 x-0.2 x^{2}\right)$

and 7(b)-3 show that increasing the remanufacturing rate leads to an increase in the threshold value, the expected profit, and the accepted returned.

The results for the sensitivity analysis of $\alpha$ and $\gamma$ are shown in Table 1 . The values of the threshold, the acceptance percentage and the expected total discounted profit for each value of $\gamma$ and $\alpha$ are written in the table as $\left(k^{*}, F\left(k^{*}\right), V\left(k^{*}\right)\right)$. It is observed that for a constant decay rate and an increasing revenue decay rate, the expected discounted profit decreases and the threshold value increases. Therefore, the percentage of accepted returned products decreases. The results illustrate that the lower are the discount and decay rates, the higher is the profit for the remanufacturing system.

Table 1: Impact of regular discount and revenue decay rates $\left(\lambda_{m}=0.5\right.$ and $\left.\mu_{m}=0.7\right)$

\begin{tabular}{c|cccc}
\hline \multirow{2}{*}{$\alpha$} & \multicolumn{4}{|c}{$\gamma$} \\
\cline { 2 - 5 }$\alpha$ & 0.003 & 0.005 & 0.007 & 0.009 \\
\hline 0.01 & $(11.31,1.00,2725.3)$ & $(11.63,1.00,2338.4)$ & $(11.64,1.00,2042.8)$ & $(11.71,1.00,1809.6)$ \\
\hline 0.02 & $(8.02,0.99,1465.8)$ & $(9.15,1.00,1334.8)$ & $(9.44,1.00,1223.6)$ & $(9.47,1.00,1127.9)$ \\
\hline 0.03 & $(4.71,0.96,976.5)$ & $(6.38,0.99,908.0)$ & $(7.02,0.99,849.0)$ & $(7.25,1.00,798.3)$ \\
\hline 0.05 & $(1.82,0.72,593.6)$ & $(3.16,0.90,535.5)$ & $(3.78,0.93,506.0)$ & $(4.11,0.94,482.2)$ \\
\hline
\end{tabular}

The cost-time curves impacts on the profit and the threshold value are shown in Table 2 . The variability cost-time curves are modeled by two parameters $\left(b_{1}, b_{2}\right)$. The general form of this curve is $r_{0}(x)=b_{2} x^{2}+b_{1} x+b_{0}$. Recall that Figure 5 shows the different kinds of cost-time curves. The 

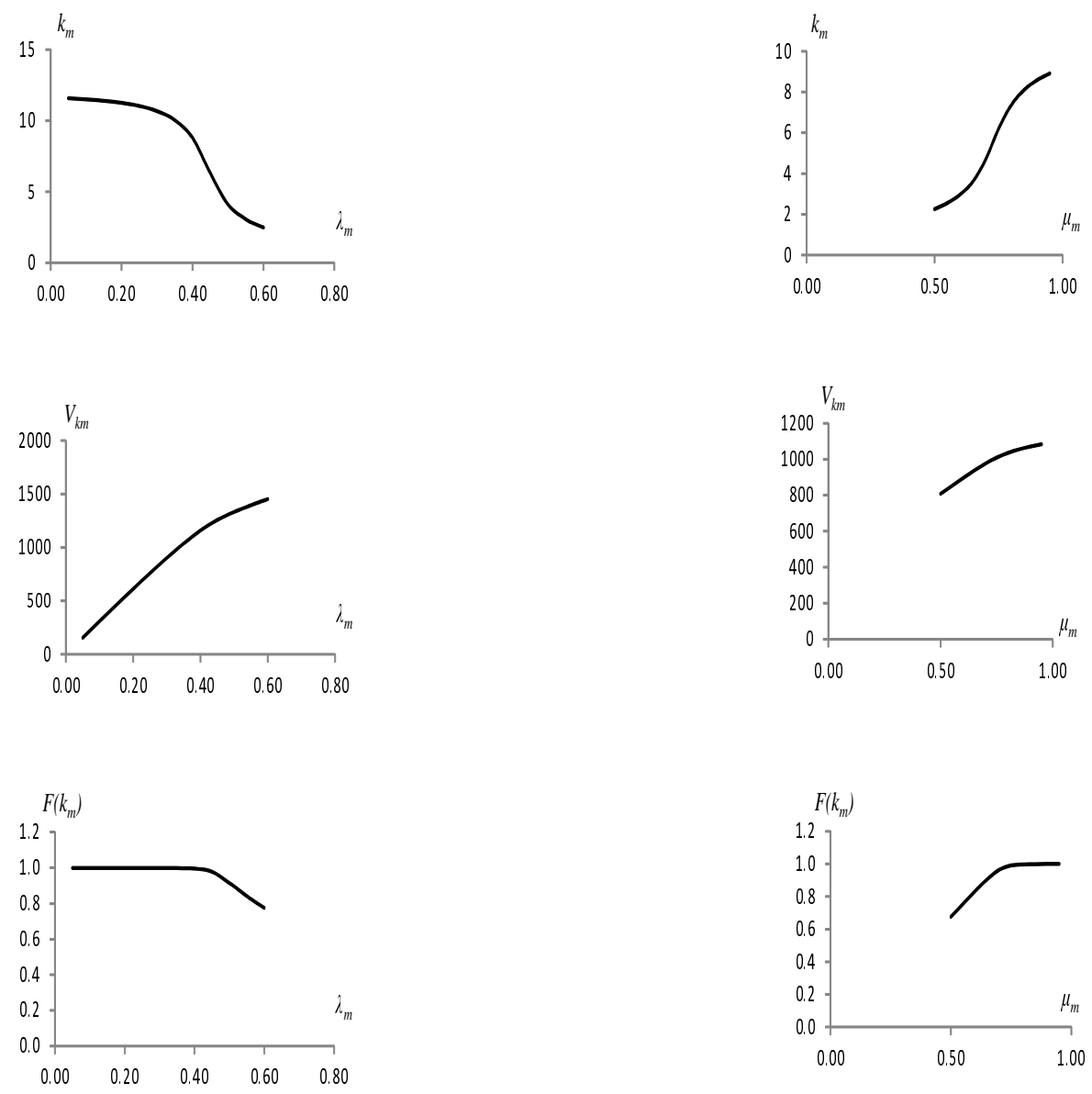

(a) $\mu_{m}=0.6$

(b) $\lambda_{m}=0.5$

Figure 7: Threshold, profit and acceptance percentage $\left(\gamma=0.003, \alpha=0.02, p=3\right.$ and $r_{0}(x)=$ $\left.80-2.5 x-0.2 x^{2}\right)$

profit increases with a decreasing in the value of cost-time curves. The amount of the admission value $\left(k_{i}\right)$ is enhanced by an increasing in the parameter of the cost-time curves. In the last values of the parameter in the curve, $100 \%$ of the returned products are accepted under the threshold 8.02 and then the profit is maximized among other values. It is important to mention that the shape of the cost-time curves is an exogenous factor which cannot be controlled by the system manager.

The same analysis is done for returned products from Market $H$. The sensitivity analysis of the threshold value and the expected profit function (Equation (9)) versus the system parameters is shown in Figures $8(\mathrm{a})$ and $8(\mathrm{~b})$ with $\mu_{h}=0.6$ and $\lambda_{h}=0.5$. We observe that an increase in the returned products rate with a constant remanufacturing rate leads to a decrease in the threshold value (Figure 8(a)-1), an increase in the expected profit and the acceptance percentage (Figure 8(b)2 and Figure 8(a)-3). Moreover, Figures 8(b)-1 and 8(b)-3 reveal that the threshold values and the 
Table 2: Impact of cost-time curves $\left(\mu_{m}=0.6, \lambda_{m}=0.4, p=3\right)$

\begin{tabular}{c|cccc}
\hline \multirow{2}{*}{} & \multicolumn{4}{|c}{$\left(b_{1}, b_{2}\right)$} \\
\cline { 2 - 5 } & $(-5,-1.2)$ & $(-4,-0.8)$ & $(-3,-0.5)$ & $(-2.5,-0.2)$ \\
\hline$k$ & 4.05 & 4.78 & 5.88 & 8.02 \\
\hline$F(k)$ & 0.941 & 0.965 & 0.984 & 1.00 \\
\hline$V(k)$ & 1349.40 & 1391.00 & 1432.60 & 1465.80 \\
\hline
\end{tabular}

acceptance percentage for different values of the remanufacturing rate are approximately constant. For some critical value of the remanufacturing rate, the expected profit is collapsed (Figure 8(b)-2), while the trend is ascending. This critical value has an important role in a situation of an increasing dedicated remanufacturing capacity.

The results of the sensitivity analysis for $\alpha$ and $\gamma$ are shown in Table 3. The threshold, the acceptance percentage and the expected total discounted profit for each value of $\gamma$ and $\alpha$ are shown as $\left(k^{*}, F\left(k^{*}\right), V\left(k^{*}\right)\right)$. For constant decay rate and increasing discount rate, the expected discounted profit decreases. The result shows that the low discount and decay rates have more profit for the remanufacturing system. The threshold value and the percentage of the accepted returned products do not have a sensitivity in $\gamma$ and $\alpha$.

Table 3: Impact of discount and decay rates $\left(\lambda_{h}=0.6\right.$ and $\left.\mu_{h}=0.8\right)$

\begin{tabular}{c|cccc}
\hline \multirow{2}{*}{$\alpha$} & \multicolumn{4}{|c}{$\gamma$} \\
\cline { 2 - 5 }$\alpha$ & 0.003 & 0.005 & 0.007 & 0.009 \\
\hline 0.01 & $(1.01,0.495,551190)$ & $(1.01,0.495,287050)$ & $(1.01,0.495,181190)$ & $(1.01,0.495,126280)$ \\
\hline 0.02 & $(1.01,0.495,313900)$ & $(1.01,0.495,173530)$ & $(1.01,0.495,114940)$ & $(1.01,0.495,83360)$ \\
\hline 0.03 & $(1.01,0.495,220430)$ & $(1.01,0.495,12480)$ & $(1.01,0.495,84512)$ & $(1.01,0.495,62455)$ \\
\hline 0.05 & $(1.01,0.495,139330)$ & $(1.01,0.495,80681)$ & $(1.01,0.495,55691)$ & $(1.01,0.495,41910)$ \\
\hline
\end{tabular}

The cost-time curves impacts on the profit and the threshold are shown in Table 4. The variability of cost-time curves are modeled by two parameters $\left(b_{1}, b_{2}\right)$. A general form of this curve is $r_{0}(x)=b_{2} x^{2}+b_{1} x+b_{0}$. Figure 5 shows the different kinds of cost-time curves. 

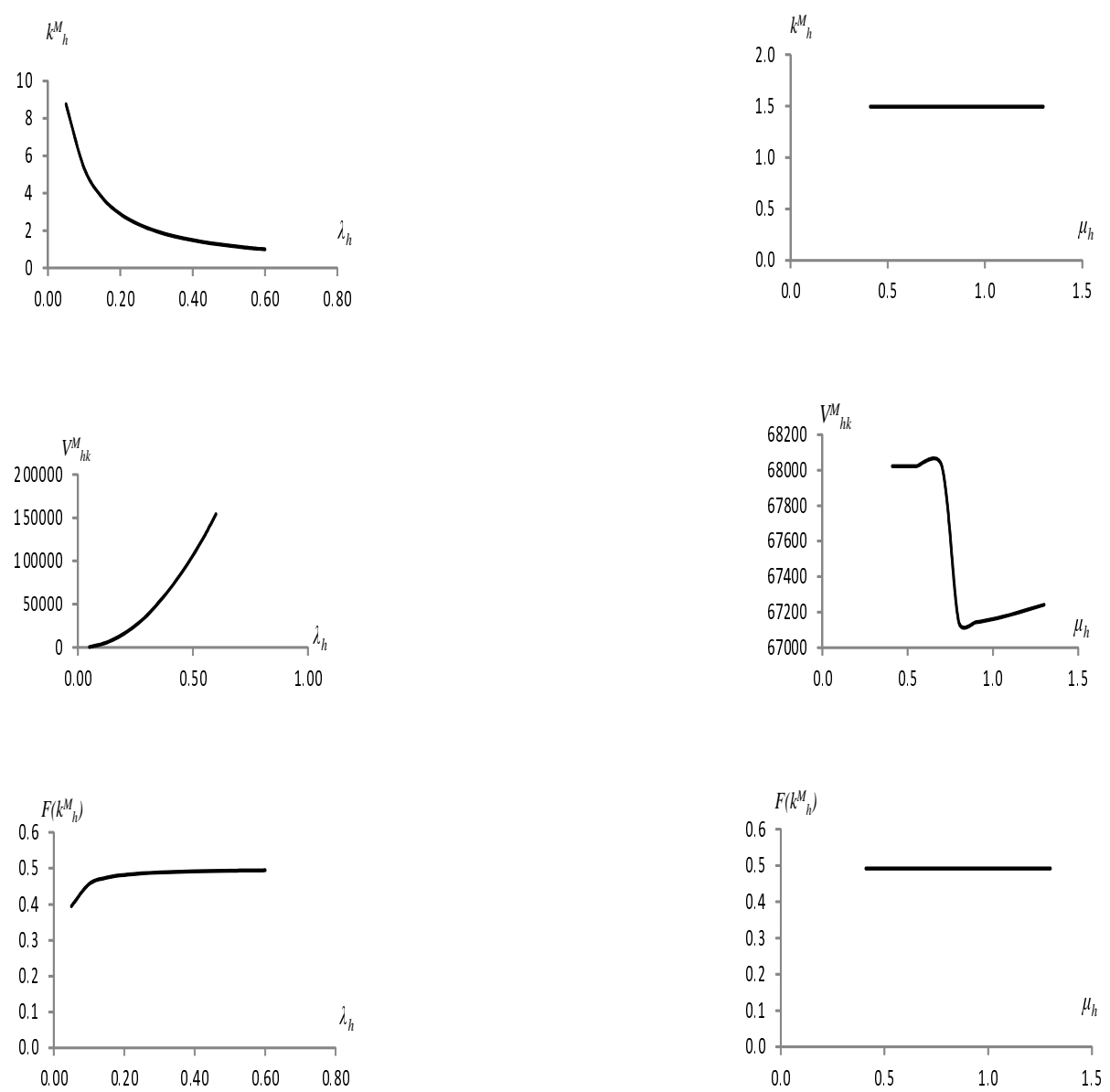
(a) $\mu_{h}=0.6$
(b) $\lambda_{h}=0.5$

Figure 8: Threshold, profit and acceptance percent for determined value of $\gamma=0.003, \alpha=0.02$, $p=3$ and $r_{0}(x)=80-2.5 x-0.2 x^{2}$

Table 4: Impact of cost-time curves $\left(\mu_{h}=0.6, \lambda_{h}=0.4, p=3\right)$

\begin{tabular}{c|cccc}
\hline \multirow{2}{*}{} & \multicolumn{4}{|c}{$\left(b_{1}, b_{2}\right)$} \\
\cline { 2 - 5 } & $(-5,-1.2)$ & $(-4,-0.8)$ & $(-3,-0.5)$ & $(-2.5,-0.2)$ \\
\hline$k$ & 0.9842 & 0.9925 & 1.0002 & 1.0051 \\
\hline$F(k)$ & 0.4881 & 0.4908 & 0.4934 & 0.495 \\
\hline$V(k)$ & 308500 & 310650 & 312700 & 313900 \\
\hline
\end{tabular}

\subsection{Analysis of the Merged System}

In each production system, the gained profit from processes is a critical criterion for the decision making. This section is devoted to analyze whether merging remanufacturing capacity can increase 
the profit at each returned product stream and to determine the Pareto improving region. For this purpose a key performance measure is defined as the expected profit improvement, $\Delta V=$ $V_{\text {merged }}-V_{\text {seperated }}$.

We examine the sensitivity analysis of Market $\mathrm{M}$ by the performance indicator $\Delta V$ as it moves from a separated system to a merged system. By moving to a merged system, Market M sees additional remanufacturing capacity but has to share that capacity with some load from Market H. In Figure 9, the profit variability for returned products from Market $M$ when considering different values of $\lambda_{m}$ and $\lambda_{h}$ in the merged system is shown. The results show that irrespective of relative loads, Market M often sees an improvement in its performance measures.

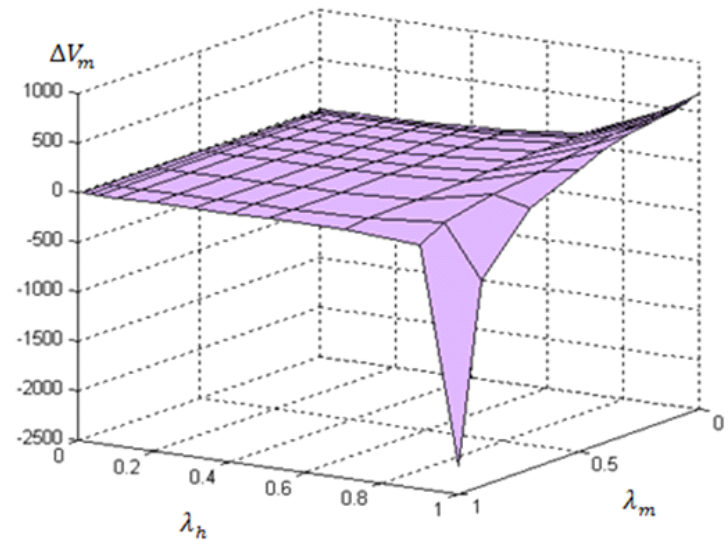

(a)

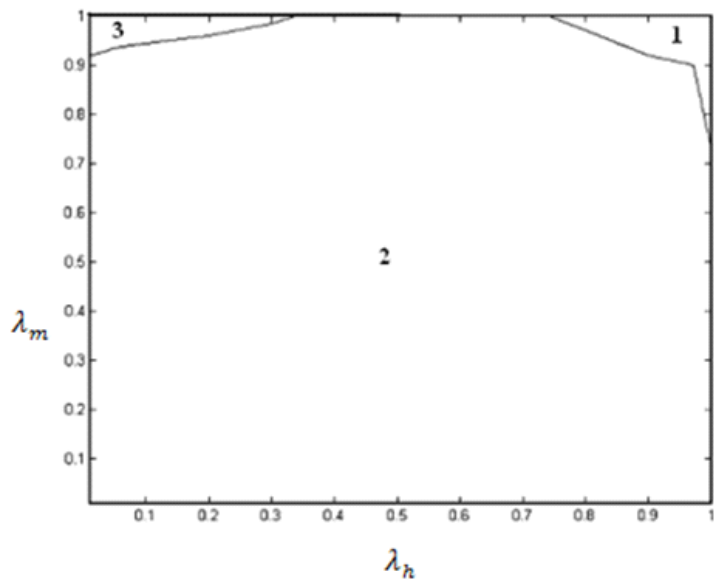

(b)

Figure 9: Profit variability for returns from Market M, in the merged capacity configuration

In Figure 9, Region 1 has $\Delta V<0$ and Market M prefers a separated capacity. For a large value of returned product rate from Markets $\mathrm{M}$ and $\mathrm{H}$ (approximately $\lambda_{m}, \lambda_{h}>0.8$ ), it is preferred for Market $M$ to merge the capacity of the remanufacturing facility. So, when the capacity of remanufacturing is merged and the variability of the two markets is high, Market M prefers to remanufacture its returned products under a separated capacity system. The performance measure of Region 2 is positive $(0<\Delta V<500)$. Region 3 has high positive performance measures $(\Delta V>$ $500)$.

Figure 10 shows the sensitivity analysis of Market $\mathrm{H}$ through the performance measure $\Delta V$ as it moves from a separated system to a merged system. For a small value of the returned products rate from Market $\mathrm{H}\left(\lambda_{h}<0.05\right)$, Market $\mathrm{H}$ has no improvement in the expected profit (performance measure $\Delta V=0)$. In Figure 10, this region is illustrated by Region 3. In this region, merged and 
separated capacities have equal profit. Also Region 1 has no preference for merging or separating. The performance measure in Region 3 is negative $(\Delta V<0)$. Therefore, a septated capacity is preferred for Market H.

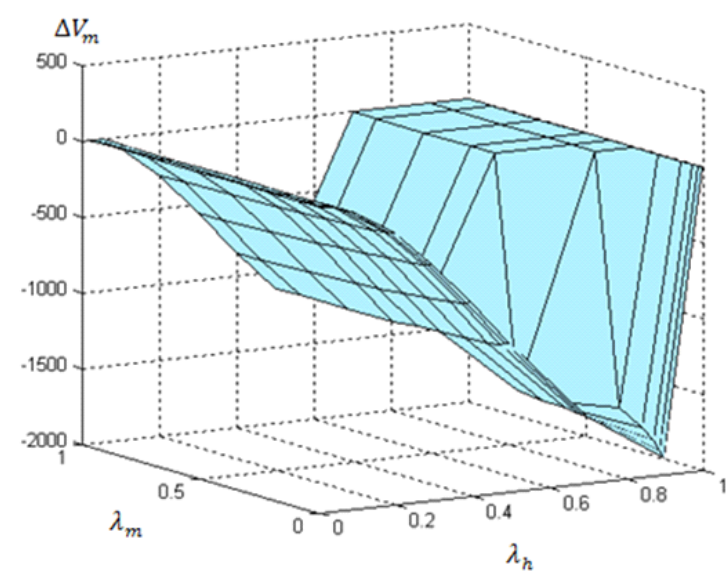

(a)

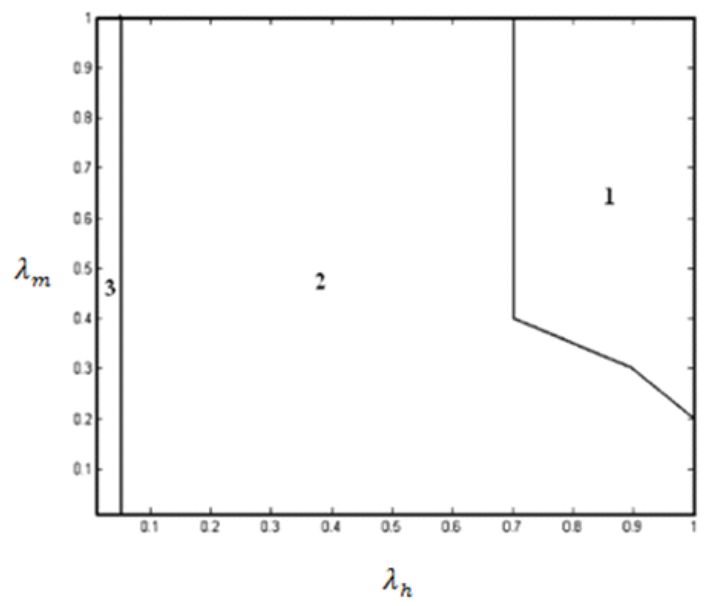

(b)

Figure 10: Profit variability for returns from Market H, in the merged capacity system configuration

The Pareto-improving criterion requires that neither returned product streams from the markets should see a profit decrease and at least one should see a profit increase. The results shown in Figures 9 and 10 show that merging generates Pareto-improving benefits in most of the cases. In our proposed model there is a single server remanufacturing. From the point of view of the remanufacturing facility, there is one beneficiary of the two streams; therefore the profit of the remanufacturing is the sum of the two profits. The expected profit improvement of each market can be seen as a whole $\left(\Delta V_{m}+\Delta V_{h}\right)$. Figure 11 shows the difference between the expected profit for merged and separated capacity configurations.

The performance measures of Regions 1 and 3 are negative and the remanufacturing system prefers a separated capacity. Region 2 has $\Delta V=0$, therefore, merged and separated capacities have no impact on profit. For small values of returned product rate from Market H (approximately $\lambda_{h}<$ 0.2 , the remanufacturing system prefers to merge the capacity which is shown by Regions 4 and 5. Region 5 is the area with low values of the returned products rates from Market $\mathrm{H}\left(\lambda_{h}<0.1\right)$ and high values of the returned products rate from Market $\mathrm{M}\left(\lambda_{m}>0.9\right)$. In this region, the improvement in the expected profit in merged capacity is greater than 500 . 


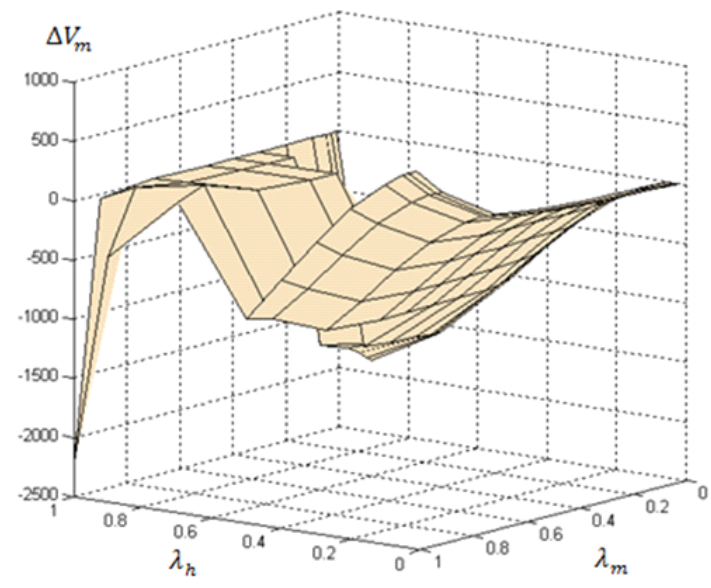

(a)

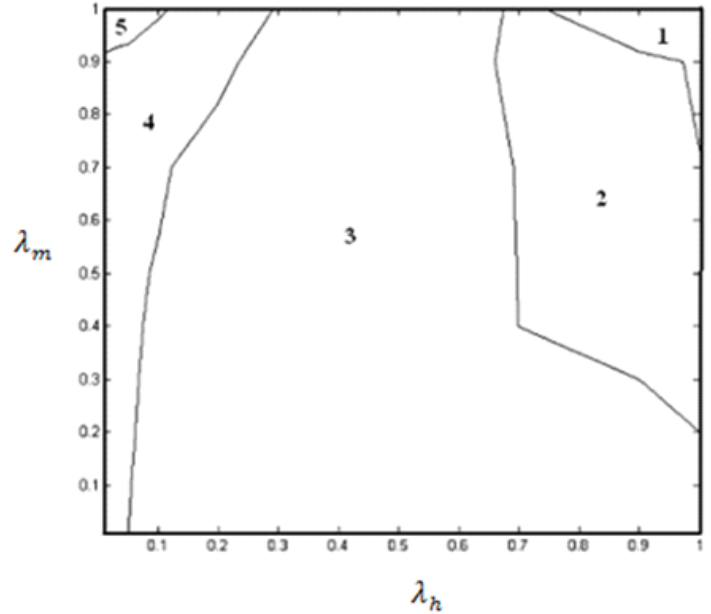

(b)

Figure 11: The difference between gained expected profit for merged and separated capacity

\section{Conclusions and Future research}

A remanufacturing system is considered to analyze and optimize a type of short life cycle products with stochastic serviceable products demand and stochastic processes of returned products. High congestion of returned products at the remanufacturing facility leads to a substantial delay and consequently remarketing value losses for time-sensitive products and high-tech products with short life cycles, such as electronic equipments.

The remanufacturing process was modeled by the $\mathrm{M} / \mathrm{M} / 1, \mathrm{H} / \mathrm{M} / 1$, and $\mathrm{H}_{2} \mathrm{M} / \mathrm{M} / 1$ queueing systems, which led us to two new lessons. First, determining the admission decision threshold value which decides about the acceptance of the returned products based on the quality and the processing time. The objective is being to maximize the total expected profit of the remanufacturing system. Second, the $\mathrm{H}_{2} \mathrm{M}$ model shows that the difference in variability of arrivals has a significant impact on the value of merging capacity. Our analysis of the $\mathrm{H}_{2} \mathrm{M}$ model allows us to study the interaction between the overall utilization and the arrival variability. This basic understanding of the impact of variability on merging value will be helpful for managers planning to merge the production capacities. We have also addressed the question of when does merging generate Pareto-improving benefits over the separated system. The analysis was illustrated through a numerical study. The results show the significant impact of the model parameters on the admission decision and the total expected discounted profit. Moreover, we have compared between the total expected discounted profits under situations of separated and merged capacities. 
In a future research, it would be interesting to consider queueing capacity constraints for the returns. One would also include an inventory cost analysis for the warehousing of remanufactured products. Another interesting but at the same time challenging future direction is to consider a capacity constraint for the testing stage and also more general arrival processes for returns.

\section{References}

Aksoy, H. and Gupta, S. (2005). Buffer allocation plan for a remanufacturing cell. Computers $\&$ Industrial Engineering, 48(3):657-677.

Albin, S. (1984). Approximating a point process by a renewal process, ii: Superposition arrival processes to queues. Operations Research, 32(5):1133-1162.

Altiok, T. (1989). Approximate analysis of queues in series with phase-type service times and blocking. Operations Research, 37(4):601-610.

Aras, N., Boyaci, T., and Verter, V. (2004). The effect of categorizing returned products in remanufacturing. IIE transactions, 36(4):319-331.

Bayindir, Z., Erkip, N., and Gullu, R. (2003). A model to evaluate inventory costs in a remanufacturing environment. International Journal of Production Economics, 81(3):597-607.

Bayindir, Z., Erkip, N., and Gullu, R. (2004). Assessing the benefits of remanufacturing option under one-way substitution. Journal of the Operational Research Society, 56(3):286-296.

Bayindir, Z., Erkip, N., and Gullu, R. (2007). Assessing the benefits of remanufacturing option under one-way substitution and capacity constraint. Computers $\& 3$ operations research, 34(2):487514.

Behret, H. and Korugan, A. (2005). The impact of quality uncertainty of returns in remanufacturing. In Proceedings of the 35th international conference on Computers $\mathcal{E}$ Industrial Engineering. Istanbul, Turkey.

Behret, H. and Korugan, A. (2009). Performance analysis of a hybrid system under quality impact of returns. Computers $\&$ Industrial Engineering, 56(2):507-520. 
Ching, W. (2001). Iterative methods for queuing and manufacturing systems. Springer Monographs in Mathematics, Springer-Verlag, London.

Ching, W., Li, T., and Xue, G. (2007). On hybrid re-manufacturing systems: A matrix geometric approach. In Proceedings of the International Conference on Industrial Engineering and Systems Management.

Ching, W., Yuen, W., and Loh, A. (2003). An inventory model with returns and lateral transshipments. Journal of the Operational Research Society, 54(6):636-641.

Dekker, R., Fleischmann, M., and Inderfurth, K. (2004). Reverse logistics: quantitative models for closed-loop supply chains. Springer, Berlin.

Dobos, I. and Richter, K. (2006). A production/recycling model with quality consideration. International Journal of Production Economics, 104(2):571-579.

Eisenstein, D. and Iyer, A. (1996). Separating logistics flows in the chicago public school system. Operations Research, 44(2):265-273.

Ferguson, M., Guide, V., Koca, E., and Souza, G. (2006). Remanufacturing planning with different quality levels for product returns. Robert H. Smith School Research Paper No. RHS, pages 06-050.

Fisher, M. (1997). What is the right supply chain for your product? Harvard Business Review, $75(2): 105-117$.

Flapper, S., Gayon, J., and Lim, L. (2014). On the optimal control of manufacturing and remanufacturing activities with a single shared server. European Journal of Operational Research, 234(1):86-98.

Galbreth, M. and Blackburn, J. (2006). Optimal acquisition and sorting policies for remanufacturing. Production and Operations Management, 15(3):384-392.

Geyer, R., van Wassenhove, L. N., and Atasu, A. (2007). The economics of remanufacturing under limited component durability and finite product life cycles. Management Science, 53(1):88-100.

Golany, B., Yang, J., and Yu, G. (2001). Economic lot-sizing with remanufacturing options. IIE Transactions, 33(11):995-1003. 
Govil, M. and Fu, M. (1999). Queueing theory in manufacturing: A survey. Journal of manufacturing systems, 18(3):214-240.

Gross, D., Shortle, J., Thompson, J., and Harris, C. (2013). Fundamentals of queueing theory. John Wiley \& Sons, New York.

Guide, V., Gunes, E., Souza, G., and van Wassenhove, L. (2008). The optimal disposition decision for product returns. Operations Management Research, 1(1):6-14.

Guide, V., Souza, G., and van der Laan, E. (2005). Performance of static priority rules for shared facilities in a remanufacturing shop with disassembly and reassembly. European Journal of Operational Research, 164(2):341-353.

Guide, V., Souza, G., van Wassenhove, L., and Blackburn, J. (2006). Time value of commercial product returns. Management Science, 52(8):1200-1214.

Guide, V., Teunter, R., and van Wassenhove, L. (2003). Matching demand and supply to maximize profits from remanufacturing. Manufacturing $\mathcal{E}$ Service Operations Management, 5(4):303-316.

Guide, V. and van Wassenhove, L. (2003). Business Aspects of Close-loop Supply Chains. CarnegieBosch Institute, Pittsburgh.

Guide, V. and van Wassenhove, L. (2009). The evolution of closed-loop supply chain research. Operations Research, 57(1):10-18.

Gupta, D. and Gerchak, Y. (2002). Quantifying operational synergies in a merger/acquisition. Management Science, 48(4):517-533.

Ha, A. (1997). Optimal dynamic scheduling policy for a make-to-stock production system. Operations Research, 45(1):42-53.

Harrison, J. (1975). Dynamic scheduling of a multiclass queue: Discount optimality. Operations Research, 23(2):270-282.

Inderfurth, K. (2005). Impact of uncertainties on recovery behavior in a remanufacturing environment: a numerical analysis. International Journal of Physical Distribution $\&$ Logistics Management, 35(5):318-336. 
Inderfurth, K. and van der Laan, E. (2001). Leadtime effects and policy improvement for stochastic inventory control with remanufacturing. International Journal of Production Economics, 71(1):381-390.

Iyer, A. and Jain, A. (2003). The logistics impact of a mixture of order-streams in a manufacturerretailer system. Management Science, 49(7):890-906.

Iyer, A. and Jain, A. (2004). Modeling the impact of merging capacity in production-inventory systems. Management Science, 50(8):1082-1094.

Jain, A. (2007). Value of capacity pooling in supply chains with heterogeneous customers. European Journal of Operational Research, 177(1):239-260.

Jin, X., Hu, S., and Ni, J. (2012a). Assembly strategies for product remanufacturing with variable quality returns. IEEE Transactions on Automation Science and Engineering.

Jin, X., Ni, J., Hu, S., Xiao, G., and Biller, S. (2012b). Performance analysis of a remanufacturing system with warranty return admission. Working paper at University Of Michigan.

Karamouzian, A., Teimoury, E., and Modarres, M. (2011). A model for admission control of returned products in a remanufacturing facility using queuing theory. The International Journal of Advanced Manufacturing Technology, 54(1-4):403-412.

Ketzenberg, M., Souza, G., and Guide, V. (2003). Mixed assembly and disassembly operations for remanufacturing. Production and Operations Management, 12(3):320-335.

Kiesmüller, G. P. and van der Laan, E. A. (2001). An inventory model with dependent product demands and returns. International Journal of Production Economics, 72(1):73-87.

Koren, Y. (2010). The global manufacturing revolution: product-process-business integration and reconfigurable systems. John Wiley \& Sons, New Jersey.

Korugan, A. and Gupta, S. (1998). A multi-echelon inventory system with returns. Computers $\mathcal{E}$ Industrial Engineering, 35(1):145-148.

Lee, H. and Tang, C. (1997). Modelling the costs and benefits of delayed product differentiation. Management science, 43(1):40-53. 
Lund, R. and Mundial, B. (1984). Remanufacturing: The experience of the United States and implications for developing countries. World Bank, Washington, D.C.

Mahadevan, B., Pyke, D., and Fleischmann, M. (2003). Periodic review, push inventory policies for remanufacturing. European Journal of Operational Research, 151(3):536-551.

Narus, J. and Anderson, J. (1996). Rethinking distribution: Adaptive channels. Harvard Business Review, 74(4):112-120.

Perez, A. and Zipkin, P. (1997). Dynamic scheduling rules for a multiproduct make-to-stock queue. Operations Research, 45(6):919-930.

Pokharel, S. and Mutha, A. (2009). Perspectives in reverse logistics: A review. Resources, Conservation and Recycling, 53(4):175-182.

Shi, J., Zhang, G., and Sha, J. (2011). Optimal production and pricing policy for a closed loop system. Resources, Conservation and Recycling, 55(6):639-647.

Souza, G., Ketzenberg, M., and Guide, V. (2002). Capacitated remanufacturing with service level constraints. Production and Operations Management, 11(2):231-248.

Takahashi, K., Morikawa, K., Takeda, D., and Mizuno, A. (2007). Inventory control for a markovian remanufacturing system with stochastic decomposition process. International Journal of Production Economics, 108(1):416-425.

Tijms, H. (1986). Stochastic modelling and analysis: a computational approach. John Wiley \& Sons, Chichester, UK.

Toktay, L., Wein, L., and Zenios, S. (2000). Inventory management of remanufacturable products. Management science, 46(11):1412-1426.

van der Laan, E. and Salomon, M. (1997). Production planning and inventory control with remanufacturing and disposal. European Journal of Operational Research, 102(2):264-278.

van der Laan, E., Salomon, M., Dekker, R., and van Wassenhove, L. (1999). Inventory control in hybrid systems with remanufacturing. Management Science, 45(5):733-747. 
van der Laan, E. and Teunter, R. (2006). Simple heuristics for push and pull remanufacturing policies. European Journal of Operational Research, 175(2):1084-1102.

Whitt, W. (1993). Approximations for the GI/G/m queue. Production and Operations Management, 2(2):114-161.

Yamada, T., Mizuhara, N., Yamamoto, H., and Matsui, M. (2009). A performance evaluation of disassembly systems with reverse blocking. Computers $\mathcal{E}$ Industrial Engineering, 56(3):11131125.

Zipkin, P. (2000). Foundations of inventory management. McGraw-Hill, New York. 